\title{
Effects of theophylline on ventilatory response to hypoxic challenge
}

\author{
J MILERAD
}

Department of Paediatrics, Karolinska Hospital and Nobel Institute for Neurophysiology, Stockholm, Sweden

SUMMARY The respiratory and arousal responses to mild hypoxia during quiet sleep were studied using inductive plethysmography and transcutaneous gas electrodes in 11 apnoeic infants before and after the administration of oral theophylline $(3 \mathrm{mg} / \mathrm{kg})$. Theophylline changed the ventilatory response to a more biphasic pattern - that is, ventilation decreased after an initial increase. The relative ventilatory slope (defined as the decrease in transcutaneous carbon dioxide tension $\left(\mathrm{PCO}_{2}\right)$ in relation to the fall in transcutaneous oxygen tension $\left(\mathrm{PO}_{2}\right)$ ) decreased significantly after theophylline. Four infants were roused during hypoxia before theophylline administration compared with none after treatment. Theophylline abolished the periodic breathing induced by hypoxia in one of six infants. These findings suggest that methylxanthines may not, as previously thought, enhance the respiratory drive during hypoxia.

Methylxanthine derivatives are widely used as respiratory stimulants both in low birthweight infants with idiopathic apnoea and in those with apnoea of infancy. These compounds increase the respiratory drive and reduce the number of apnoeic episodes both in premature ${ }^{12}$ and older apnoeic infants. ${ }^{34}$ Theophylline has also been assumed to increase the ventilatory and arousal responsiveness to hypoxia in babies with apnoea of infancy. ${ }^{3}$ Experimental studies in newborn animals, however, have shown contradictory results. ${ }^{56}$ In man investigations have so far only been performed in adults. ${ }^{78}$

The aim of this study was to investigate whether theophylline given before a hypoxic challenge increased the ventilatory and arousal responsiveness. Two hypoxic challenges, one before and one after the administration of theophylline, were performed during the same night in 11 infants with severe apnoeic events associated with sleep.

\section{Patients and methods}

The study was approved by the local ethical committee and informed parental consent was obtained in all cases. Seven boys and four girls who had had a potentially life threatening apnoeic episode were entered in the study. Their median age at the time of the recording was 10 weeks (range 3-21). These 11 infants were part of a larger group of apnoeic infants recently evaluated in a prospective collaborative study. ${ }^{9}$

The respiratory investigations comprised a 10 minute hypoxic challenge with $15 \%$ oxygen in nitrogen. A warmed and humidified hypoxic gas mixture was delivered at a rate of $6-8 \mathrm{l} /$ minute through a $10 \mathrm{l}$ plastic hood covering the head and neck. The tests were performed in standardised conditions (the environmental temperature was $24^{\circ} \mathrm{C}$, and the lights were dimmed) during quiet sleep. ${ }^{10}$ The control test was carried out between 9 and $11 \mathrm{pm}$. The infants were lying prone and after a five minute stable control period in air the hypoxic gas mixture was delivered for 10 minutes. The test was repeated between 0 and 2 am, about one hour after administration of an oral dose of theophylline cholinate $3 \mathrm{mg} / \mathrm{kg}$.

Recordings during uninterrupted natural sleep were a matter of prime concern in the investigation; to avoid the disturbance of blood sampling plasma theophylline concentrations were not determined.

The ventilatory response to hypoxia was assessed by inductance plethysmography (Respitrace, Ambulatory monitoring, Ardsley, New Jersey, USA). Minute ventilation was defined as the sum of the rib cage and abdominal movements during each minute of the test. The inductance plethysmography device was calibrated in arbitrary units and ventilation was expressed as the percentage change from the control period. 
In addition, an index of ventilatory responsiveness to hypoxia in relation to the prevailing metabolic needs was calculated from the trancutaneous gas changes. This index, 'relative ventilatory slope', is defined below; a more extensive justification for this approach has been given elsewhere. ${ }^{11}$

Transcutaneous electrodes (Radiometer TCM1 and TCM2, Copenhagen, Denmark) were used to estimate arterial gas pressures. The probes were positioned on the abdomen at the costal margin. A $45^{\circ} \mathrm{C}$ temperature setting was used for the transcutaneous oxygen $\left(\mathrm{tcPO} \mathrm{PO}_{2}\right)$ and $43^{\circ} \mathrm{C}$ for the transcutaneous carbon dioxide $\left(\mathrm{tcPCO}_{2}\right)$ electrode. The $\mathrm{tcPO}_{2}$ electrode was calibrated to ambient barometric pressure and the tcPCO 2 electrode to two carbon dioxide mixtures of known concentration.

The principles of the data analysis are illustrated in a representative recording from one patient (fig 1). $\mathrm{TcPO}_{2}$ values were taken from the original tracing every 15 seconds and paired with the
tcPCO 2 values obtained 60 seconds later (fig 1, top). This correction was made to compensate for the delay of the $\mathrm{tcPCO}_{2}$ electrode.

The relative ventilatory slope was defined as the change in $\mathrm{tcPCO}_{2}$ in relation to the fall. in $\mathrm{tcPO}_{2}$. Each deflection from the control value of $t \mathrm{PCO}_{2}$ $(\triangle \mathrm{tcPCO})_{2}$ was plotted against the corresponding inverted $\mathrm{tcPO}_{2}$ value and a regression line was fitted, using the method of least squares (fig 1, middle).

A negative relative ventilatory slope suggested a relative increase in ventilation, because $\mathrm{tcPCO}_{2}$ decreased in response to the hypoxic challenge. Correspondingly, a positive slope was taken as showing a relative decrease in ventilation because $\mathrm{tcPCO}_{2}$ increased in response to the hypoxic provocation. The mean rate of decrease in $\mathrm{tcPO}_{2}$ was also calculated by regression analysis. The curvilinear decay of the $\mathrm{tcPO}_{2}$ is shown by plotting the $\mathrm{tcPO}_{2}$ values on a semilogarithmic scale (fig 1 ,
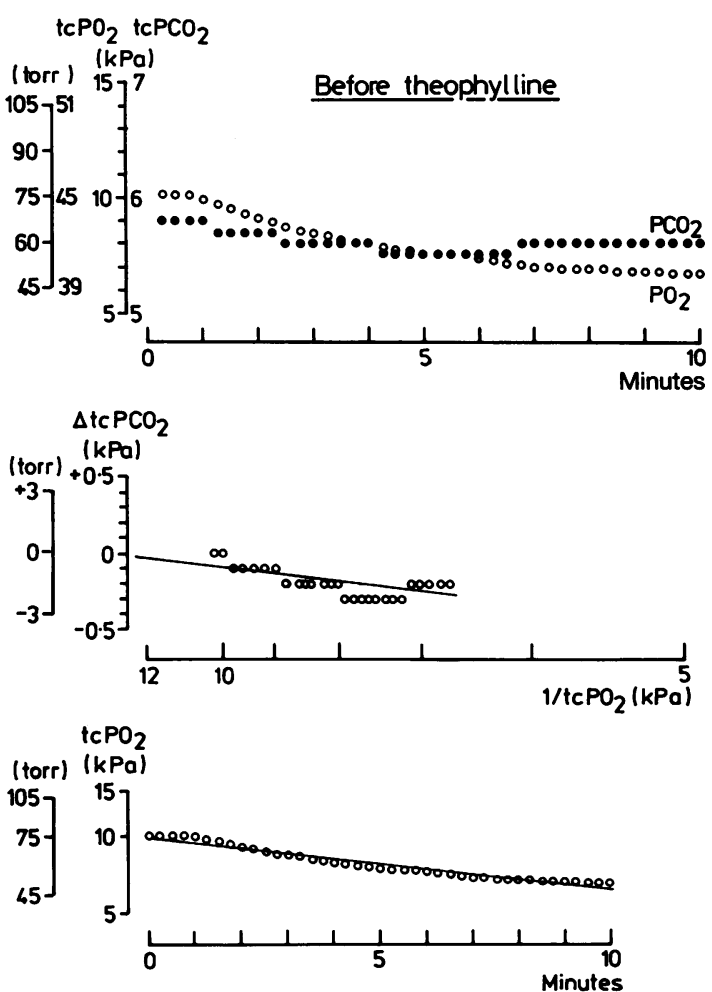
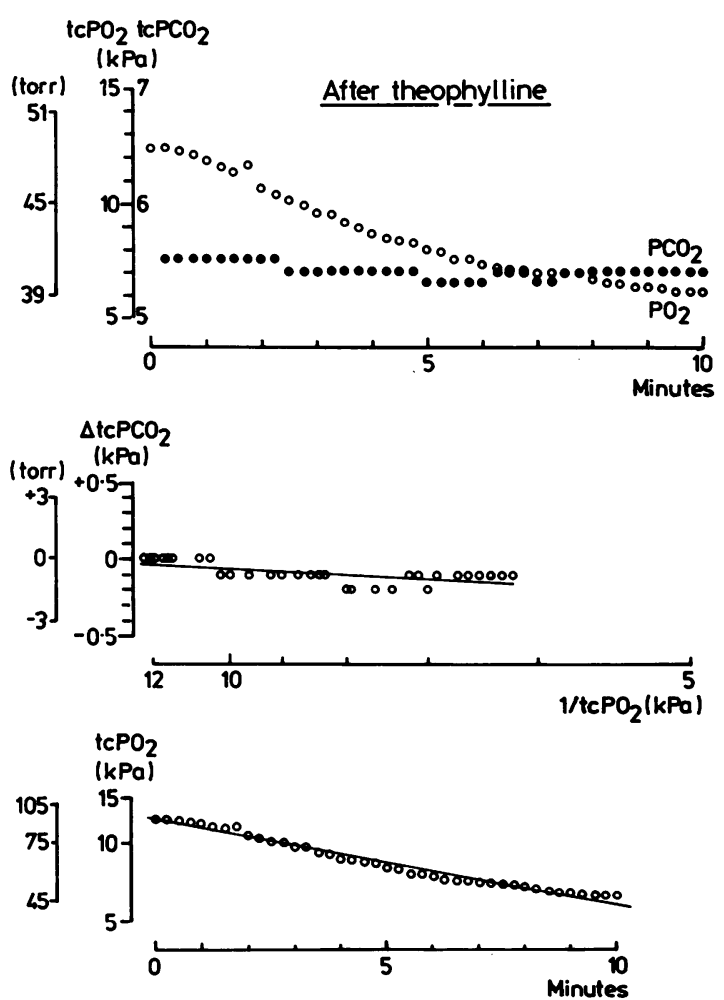

Fig 1 Transcutaneous oxygen and carbon dioxide measurements recorded during one hypoxic episode in a 6 week old girl with apnoea of infancy. Top- $\mathrm{tcPO}_{2}$ and $t c \mathrm{PCO}_{2}$ sampled every 15 seconds during 10 minute test. Middle-Regression line representing relative ventilatory slope. Each deflection from control tcPCO$\left(\triangle t c P C \mathrm{O}_{2}\right)$ is plotted against corresponding inverted tcPO $\mathrm{Palue}_{2}$. Negative slope indicates relative increase in ventilation. Bottom-Regression line representing rate of $\mathrm{tcPO}_{2}$ decrease. $\mathrm{TcPO}_{2}$ curve of bottom panel is plotted on a semilogarithmic scale. 
bottom). The main purpose of this analysis was to relate the occurrence of hypoxic arousal to the rate of fall in $\mathrm{PO}_{2}$.

Periodic breathing was defined as three or more regularly recurring episodes of respiratory arrests of more than 3 seconds in duration interrupted by periods of regular breathing of less than 20 seconds. Arousal was defined as crying and opening of the eyes or signs of discomfort and gross body movements for at least 20 seconds. The $\mathrm{tcPO}_{2}$ and tcPCO $\mathrm{C}_{2}$ values of the last minute prior to the test were used as baseline measurements.

The respiratory data of each baby before and after the administration of theophylline were compared by Student's $t$ test, repeated measures design. Fisher's exact test was used to assess the significance of differences in incidence of arousal and periodic breathing before and after treatment. Regression analysis was used to determine slopes and relations.

\section{Results}

Most infants increased their ventilation about $20 \%$ over the control period in response to the hypoxic provocation and sustained this increase throughout the 10 minutes of hypoxia (fig 2). After administration of theophylline a similar increase in ventilation was observed. The rise in ventilation, however, was not sustained to the same extent as before treatment (fig 2). Although the ventilatory response to hypoxia varied considerably among individual babies, the altered response pattern after theophylline administration was a consistent observation.

The effect of theophylline on $\mathrm{tcPO}_{2}$ and $\mathrm{tcPCO}$ measurements in a six week old girl is shown in fig 1 ; her response pattern was representative of the whole group of infants. After theophylline adminis-

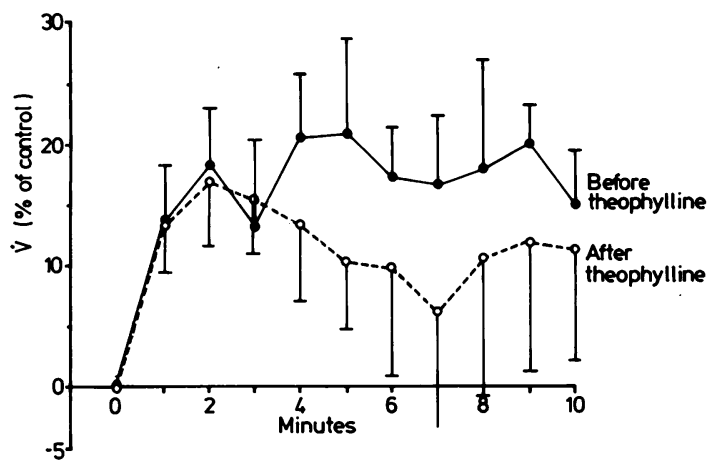

Fig 2 Minute ventilation during hypoxia assessed by inductive plethysmography. Mean (SD) ventilatory response $=\%$ of control; matched data only included. tration there was a significant increase in mean (SD) baseline tcPO $\mathrm{PO}_{2}$ tension $(1.8(1.6) \mathrm{kPa} ; \mathrm{p}<0.005)$ and a significant decrease in mean (SD) baseline tcPCO tension $(0.5(0.4) \mathrm{kPa} ; \mathrm{p}<0.0009)$. The relative ventilatory slope (non-dimensional index) decreased on average $1.6(1.5)(p<0.02)$ after theophylline, indicating a relative decrease in ventilation.

The mean rate of decrease of $\mathrm{tcPO}_{2}$ during the hypoxic challenge was not significantly affected by theophylline. The average decrease (here expressed in logarithmic units as $-\log _{e} \mathrm{kPa} /$ minute) was $-0.059(0.028)$ before and $-0.064(0.028)$ after treatment. The mean lowest $\mathrm{tcPO}_{2}$ tension remained unchanged, being $5 \cdot 2(1.4) \mathrm{kPa}$ before and $5.5(1.5) \mathrm{kPa}$ after theophylline administration.

All infants breathed regularly during the control period. Theophylline abolished periodic breathing induced by hypoxia in only one of the six infants who had this breathing pattern before treatment. Four infants were roused before theophylline administration compared with none after treatment.

\section{Discussion}

The two main findings of this study are that theophylline does not increase ventilatory responsiveness to hypoxia, and it has no consistent effects on the periodic breathing induced by hypoxia. Furthermore, arousal responsiveness seemed to decrease after treatment with theophylline. These effects of theophylline during hypoxia contrast strongly with its well known stimulatory effects on respiration during air breathing.

After theophylline administration baseline $\mathrm{tcPO}_{2}$ tension increased and baseline $\mathrm{tcPCO}_{2}$ tension decreased significantly. This suggests an increase in resting ventilation, which confirms previous observations. ${ }^{1}$ Because tcPO $\mathrm{O}_{2}$ tensions were higher and those of $\mathrm{tcPCO}_{2}$ lower after theophylline adminstration, a less pronouced immediate ventilatory response to hypoxia could be expected due to the lower chemoreceptor stimulation, both peripherally and centrally. This was not found, as the degree of the initial ventilatory response was not affected by theophylline. The immediate response to hypoxia is largely mediated by carotid body chemoreceptor activity, and therefore the unchanged responsiveness (in spite of higher baseline tcPO $\mathrm{P}_{2}$ tensions) may suggest that theophylline has some stimulatory effects on peripheral chemoreceptors. ${ }^{12}$

The hypoxic respiratory responsiveness was estimated by analysing the changes in $\mathrm{tcPCO}_{2}$ in relation to the fall in $\mathrm{tcPO}_{2}$. Measurements of pulmonary ventilation alone may not be adequate to interpret the hypoxic ventilatory response in infants 
because any observed changes in ventilation may also be secondary to changes in metabolic rate. This was particularly true in the present investigation because theophylline increases oxygen consumption even in the low dose used. ${ }^{1}$

The main purpose of analysing the transcutaneous gas changes was to distinguish between a real ventilatory depression-that is, a decrease in ventilation accompanied by a rise in $\mathrm{PCO}_{2}$ and a -decrease in ventilation with no increase in $\mathrm{PCO}_{2}$ that is, a decrease probably appropriate for the prevailing metabolic demands. Another aim was to relate the response to actual $\mathrm{PO}_{2}$ concentrations as the same fraction of inspired oxygen may produce different degrees of hypoxia in two different tests due to differences in resting concentrations of $\mathrm{PO}_{2}$ and body oxygen stores.

The initial increase in ventilation was not sustained to the same extent after theophylline. This late fall seemed to reflect a real decrease in alveolar ventilation because the index of $t \mathrm{PCO}_{2}$ decrease in relation to the fall in tc $\mathrm{PO}_{2}$ diminished significantly.

Similar effects of theophylline on the response characteristics-that is, unchanged initial ventilatory response followed by a decrease-have previously been seen in a more extensive investigation of piglets paralysed and servoventilated after vagotomy. ${ }^{6}$ The increase in ventilatory drive during hypoxia (measured as phrenic discharge) was less sustained after theophylline administration.

The mechanisms producing this late fall in ventilation are obscure, and there may be several explanations. Adenosine is released in the brain during hypoxia ${ }^{13}$ where it depresses ventilation by a central mechanism, ${ }^{14}$ and increases breathing via peripheral chemoreceptors. ${ }^{15}$ Many of the respiratory effects of theophylline are mediated by its antagonistic effects on adenosine. ${ }^{16}$ Adenosine is released in the brain at a lower $\mathrm{PO}_{2}$ than in peripheral tissues. ${ }^{17}$ During this relatively mild hypoxia theophylline may have interfered mainly with the peripheral actions of adenosine, that is, its stimulatory effects on carotid chemoreceptors.

An alternative explanation is that theophylline (by decreasing cerebral blood flow velocity ${ }^{18}$ and by lowering arterial $\mathrm{PCO}_{2}$ ) may make the brain hypoxaemic leading to a decrease in ventilation. ${ }^{19}$ This mechanism could also explain the lower rate of arousal seen after treatment. A decrease in cerebral blood flow interferes with the ability to become aroused. ${ }^{20}$

The original observation by Vogl that methylxanthines abolish periodic breathing when breathing air has been repeatedly confirmed in both infants and adults. ${ }^{21}$ In his study no clear-cut effects on periodic breathing induced by hypoxia were observed.
Cherniack et al have shown that in adult cats an increased hypoxic drive (a decrease in $\mathrm{PO}_{2}$ ) in conjunction with a decreased carbon dioxide drive (a decrease in $\mathrm{PCO}_{2}$ ) can elicit regular periodic breathing. ${ }^{22}$ Theophylline has been reported to shift the carbon dioxide response curve to the left. ${ }^{1}$ This change in carbon dioxide threshold may counteract the stabilising effects of theophylline on respiratory control.

In healthy adults aminophylline has been reported to increase hypoxic ventilatory responsiveness, but only when alveolar $\mathrm{PCO}_{2}$ was raised to pretreatment concentrations. ${ }^{78}$ It was therefore concluded that methylxanthines increase hypoxic responsiveness, although this effect was masked by the relative hypocapnoea produced by these compounds. Raising the $\mathrm{PCO}_{2}$ to concentrations prevailing before theophylline administration, however, will stimulate breathing both by peripheral and central mechanisms. ${ }^{23}$ This complex interaction may not allow definite conclusions to be drawn on the responsiveness to hypoxia.

The results of this study do not contradict the view that methylxanthines may diminish the risk of sleep related apnoeic episodes by increasing baseline oxygen concentrations. They do, however, suggest that the concept of increasing hypoxic responsiveness by treatment with theophylline is questionable. To determine whether the observed decrease in the ventilatory and arousal response is of clinical importance needs further evaluation. Nevertheless, it is suggested that methylxanthines should be used with some caution in babies with apnoea of infancy.

This study was supported by the Swedish Medical Research Council (5234), the National Foundation against Heart and Lung Diseases, Allmänna BB:s minnesfond and Sällskapet barnavård. I thank associate professor Hugo Lagercrantz and professor Curt von Euler for valuable critical comments, and nursery nurse Siv Öhman-Spetz for technical assistance.

\section{References}

1 Gerhardt T, McCarthy J, Bancalari E. Effect of aminophylline on respiratory center activity and metabolic rate in premature infants with idiopathic apnea. Pediatrics 1979;63:537-42.

${ }^{2}$ Uauy R, Shapiro DL, Smith B, Warshaw JB. Treatment of severe apnea in prematures with orally administered theophylline. Pediatrics 1975;55:595-9.

${ }^{3}$ Hunt CE, Brouillette RT, Hanson D. Theophylline improves pneumogram abnormalities in infants at risk for sudden infant death syndrome. J Pediatr 1983;103:969-74.

4 Aranda JV, Tourmen T, Davis J, et al. Effect of caffeine on control of breathing in infantile apnea. J Pediatr 1983;103: 975-8.

5 Darnall RA. Aminophylline reduces hypoxic ventilatory depression: possible role of adenosine. Pediatr Res 1985;19: 706-10.

${ }^{6}$ Long WA, Lawson EE. Neurotransmitters and biphasic ventilatory response to hypoxia. J Appl Physiol 1984;57:213-22.

${ }^{7}$ Lakshminarayan S, Sahn SA, Weil JV. Effect of aminophylline 


\section{Milerad}

on ventilatory responses in normal men. Am Rev Respir Dis 1978;115:33-8.

${ }^{8}$ Sanders JS, Berman TM, Bartlett MM, Kronenberg RS. Increased hypoxic ventilatory drive due to administration of theophylline in normal men. Chest 1980;78:279-82.

9 Milerad J, Hertzberg T, Wennergren G, Lagercrantz $H$. Ventilatory and arousal responses to hypoxia in apneic infants reinvestigated. Eur $J$ Pediatr (in press).

10 Prechtl HFR. The behavioural states of the newborn infants (a review). Brain Res 1974;76:185-212.

11 Milerad J, Hertzberg $T$, Lagercrantz $H$. Ventilatory and metabolic responses to acute hypoxia in infants assessed by transcutaneous gas monitoring. J Dev Physiol 1987;9:57-67.

12 Blanchard PW, Cote A, Hobbs S, Foulon P, Aranda JV, Bureau MA. Abolition of ventilatory response to caffeine in chemodenervated lambs. J Appl Physiol 1986;61:133-7.

13 Winn HR, Rubio R, Berne RM. Brain adenosine concentrations during hypoxia in rats. Am J Physiol 1981;241:235-42.

14 Eldridge FL, Millhorn DE, Waldrop TG, Kiley JP. Mechanisms of the respiratory effects of methylxanthines. Respir Physiol 1983;53:239-61.

15 Maxwell DL, Fuller RW, Nolop KB et al. Effects of adenosine on ventilatory responses to hypoxia in hypercapnia in humans. J Appl Physiol 1986;61:1762-6.

16 Daly JW, Bruns RF, Snuder SH. Adenosine receptors in the central nervous system: relationship to the central actions of methylxanthines. Life Sci 1981;28:2083-97.
17 Thiringer K, Blomstrand S, Hrbek A, Karlsson K, Kjellmer I. Cerebral arterio-venous difference for hypoxanthine and lactate during graded asphyxia in the fetal lamb. Brain Res 1982;3: 375-86.

18 Rosenkrantz TS, Oh W. Aminophylline reduces cerebral flow velocity in preterm infants. Am J Dis Child 1984;138:489-91.

19 Santiago TV, Neubauer JA, Edelman NH. Correlation between ventilation and brain blood flow during hypoxic sleep. $J$ Appl Physiol 1986;60:295-8

20 Santiago TV, Buerra E, Sinha AK, Edelman NH. Brain blood flow and ventilation during euoxic and hypoxic sleep. Clin Res 1980;28:431.

21 Trippenbach $T$. Effects of drugs on the respiratory control system in the perinatal period and during postnatal development. Pharmacol Ther 1983;20:307-41.

22 Cherniack NS, von Euler C, Homma I, Kao F. Experimentally induced Cheyne-Stokes breathing. Respir Physiol 1979;37: 185-200.

23 van Beek JHGM, Berkenbosch A, De Goede A, Olievier CN. Influence of peripheral $\mathrm{O}_{2}$ tensions on the ventilatory response to $\mathrm{CO}_{2}$ in cats. Resp Physiol 1983;51:279-90.

Correspondence to Dr J Milerad, Nobel Institute for Neurophysiology, Karolinska Institute, S-104 01 Stockholm, Sweden.

Received 6 July 1987 